\title{
Youth Narcissistic and Aggression: a Challenge for Guidance and Counseling Service in University
}

\author{
F. K. Fitriyah \\ Universitas Nahdlatul Ulama Surabaya \\ Surabaya, Indonesia
}

\author{
B. Purwoko \\ Universitas Negeri Surabaya \\ Surabaya, Indonesia
}

\begin{abstract}
University student is the next generation of nation that must have a good character, so must be avoided from narcissistic and aggression. The purpose of this study was to explore the phenomenon and to test the relations. Amazing results about the profile of Indonesian students about narcissistic. A study in Surabaya showed $123(38 \%)$ of 321 university students are including in narcissistic. The results of this study also show low correlation between narcissistic and aggression $(r=0.458)$, this is contrary to previous studies. Aggression in the students was dominated on verbal aggression based on the average questionnaire score (2.96) on a scale 1-5. On the other hand, physical aggression has the lowest average (2.24). Nevertheless, the problems of both narcissistic and aggression are equally important to get particular attention from guidance and counseling unit in university.
\end{abstract}

Keywords: Youth Narcissistic; Aggression; Challenge, Guidance and Counseling Service

\section{INTRODUCTION}

For some people, narcissistic behaviors needed to survive but in negative way (Maata, et al., 2012). Even narcissistic is common in humans in early adulthood (DSM-IV 1994). Early adulthood is an important period between 18-40 years (Hurlock 1999). In the study, college students are university student included in the early adult developmental period. Previous research shows increasing trend in narcissistic among university students in America [20].

Narcissistic has unfavorable impact on social and emotional relationships, since narcissistic individuals tend to be inflexible in self-improvement [3] and unrealistic in careers [4]. Narcissistic individual has very little capacity for empathy either cognitive or emotion with others $[10,17]$.

Previous studies shown positive correlation between narcissistic and aggression [19, 14, 12]. Therefore, aggression also must be studied. International Center for Research on Women (ICRW) shows 84\% students show aggression in Indonesia. In this case, Indonesia is higher than Vietnam (79\%), Nepal (79\%), Cambodia (73\%), and Pakistan (43\%) (National.republika.co.id, February 22, 2017), 259,150 cases Are aggression in women during 2016 (Kompas.com, March 7, 2017). Aggression is very harmful for human life [2].
Aggression is not just the visible behavior. According Buss (1961), aggression is divided in four aspects; physic, verbal, anger, and hostility. Physical aggression is an attack behavior that causes physical injury, whereas verbal aggression is an attacking behavior using words to threaten or rejection causing a psychical injury. Unlike the two previous aspects, anger is an emotional response that drives aggressive behavior. Whereas hostility is a restrained mind response that includes evil intent and negative evaluation about others.

Either narcissistic or aggression is not well owned by a university student. The study aimed (1) to discover the phenomena of narcissistic and aggression in university students, and (2) to find the correlations between narcissism and aggression problems in university level. And the guidance and counseling implementation service in the university will be discussed in this paper too.

\section{METHOD}

This study was conducted in the Faculty of Educational Studies, The State University of Surabaya, East Java, Indonesia. A sample was 321 aged $18-22$ years $(M=20.46)$.

This study utilized two types of scale. First, Narcissistic Personality Inventory (NPI) which was developed by Raskin and Hall in 1979 [15]. But this study used NPI in the newest version, NPI-16 which was adapted by Ames, et al. [1]. Second, Buss and Perry Aggression Questionnaire (BPAQ) which was developed by Buss A.H. and Perry M. in 1992. The aspects were physical aggression, verbal aggression, anger, and hostility, related to Buss's book "The Psychology of Aggression" in 1961. Previous study found BPAQ was proved valid and reliable to measure aggression [8], then also in Argentina's version [16] and Turki's version [6].

Both of the scales were adapted in Indonesia version. Either NPI-16 (16 items, $\alpha=0.91$ ) or BPAQ (29 items, $\alpha=0.88$ ) were proved valid and reliable. Data analyzes used descriptive statistic for the first question and Pearson Correlation for the second question. 


\section{RESULTS AND DISCUSSION}

\subsection{Narcissistic and Aggression Phenomena in College student}

The data were gathered from questionnaire of NPI-16 and BPAQ which was filled by 321 university students in The State University of Surabaya.

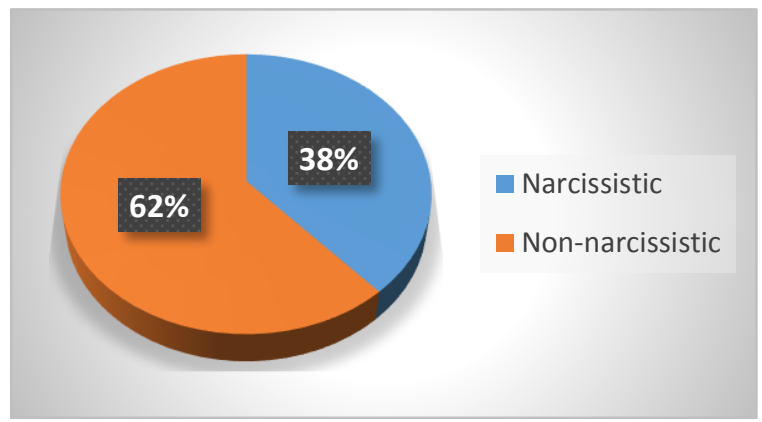

Fig. 1. The proportion of narcissitic individual in college student in the State University of Surabaya

By using NPI-16 questionnaire, figure 1 shows $38 \%$ (123) of college student in The State University of Surabaya were narcissistic. On the other hand, 62\% (198) others were nonnarcissistic.

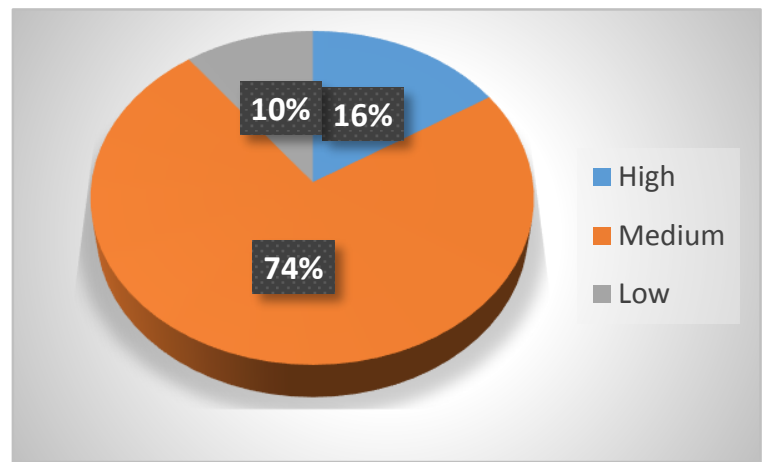

Fig. 2. The proportion of aggrassion level in college student in the State University of Surabaya

By using BPAQ, figure 2 shows $16 \%$ (51) of college student was in high aggression level and $10 \%$ (33) of it was in low aggression level. This proportion was calculated by $\mathrm{Z}$ score.

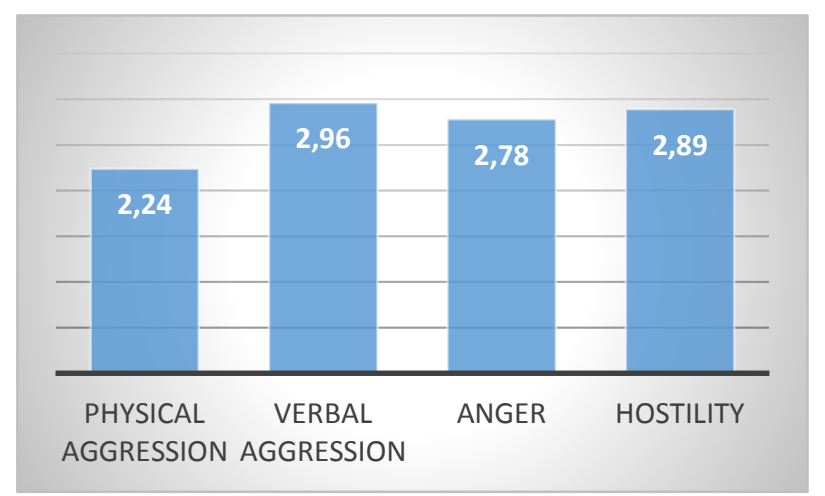

Fig. 3. The proportion of agression aspects in college student in the State University of Surabaya
Figure 3 shows the average of aggression aspects score in college student in The State University of Surabaya. By using scale 1-5, verbal aggression and hostility were the highest average score (2.96 and 2.89), whereas physical aggression was the lowest average score (2.24). Anger was in the medium position (2.78).

\subsection{The Link between Narcissistic and Aggression in College student}

In this correlation described about the relation between narcissistic and aggression, then between narcissistic and aggression aspects (physical aggression, verbal aggression, anger, and hostility). So, it can be known which aspects were most strongly related to narcissistic. The data analysis used Pearson Correlation, then it was analyzed by using SPSS 20.

By using data analysis of Pearson Correlation, it was proved a positive correlation between narcissisctic and aggression, but the correlation is rather $\operatorname{low}(\mathrm{r}=0.458)$. Further, correlation between narcissistic and aggression's aspects were low. The lowest correlation was between narcissistic and verbal aggression $(\mathrm{r}=0.231)$.

This research is based on previous studies which states that the narcissistic trend among the university students is increasing (Twenge \& Joshua 2010). Narcissistic phenomena's trend can not be avoided in individuals in this period.

The age of college students generally falls within the initial adult age range. DSM-IV (1994) mentions that this narcissistic behavior is a common disorder in humans especially in early adulthood. Hurlock (1999) states that early adulthood is age with a range between 18 years to 40 years. This early adulthood was an important period in which this period was based (Santrock, 2002), individuals worked harder in relationships with the opposite sex and left little time for anything else. Based on these views it can be concluded that the student is included in the early adult age range which has high potential for narcissistic personality disorder.

The result show $38 \%$ of college students in The State University of Surabaya are narcissistic. This percentage is high enough to require serious attention. These results are different from previous studies conducted in California. The study showed the students of psychology counseling study program did not experience narcissistic (Clark 1991).

In fact, narcissistic does not show any disturbing behavior, in fact most of them are able to socialize well (Kernberg 2004). On the other hand, the problem is dangerous much less closely related to aggression.

The result of this study shows low correlation between narcissistic and aggression $(\mathrm{r}=0.458)$. This result is very different from previous studies. Some of the assumptions that may be the reason is the media to survive for narcissistic people is quite a lot but to interact directly with others. Social media in this case has an important role in helping individuals narcissistic to survive. 
Although the correlations between narcissistic and aggression are not strong, the issue of either narcissistic or aggression is a major concern. Both are not good for students. Aggression appears to be a serious problem when viewed from BPAQ score. On the average score of aggression's aspects, from a scale of $1-5$, verbal aggression is 2.96 , hostility is 2.89 , anger is 2.78 , and physical aggression was 2.24 .

Aggression is not only visible behavior. The result of this study indicates that the aspect of hostility in aggression has the second strongest correlation with narcissistic. This proves the cognitive factor is very instrumental in the emergence of narcissistic personality disorder. On the other hand, hostility aspect in this research is one of the highest average scores. This shows that hostility is the most dominant aggression aspect compared to others.

According to Buss (1961), hostility encompasses negative thoughts about others and malice. Such thoughts may be a manifestation of self-denial of true identity. True Self in this case should be avoided because it is considered inferior, unfeasible, and not in accordance with the projected self-image. In an attempt to gain recognition, a narcissistic individual will mask his inferiority with superior self-image. This self-image then becomes façade that is so strong and visible as identity [3, $11]$.

The findings are different from Freud's views. Prior to that, Freud argued that narcissism generally arises in every individual when the libido which is psychic energy is invested in self-satisfaction so that there is an inability to invest it in others or for the benefit of others. The behavior that arises as a result of this narcissistic is seen as excessive self-love [13].

Narcissistic phenomenon in the students, especially college student is important to get a serious attention. Narcissistic tends to be closely related to lack of empathy $[10,17]$ and has a low reality level [4]. This is a challenge for counselor in university to prepare guidance and counseling service in university.

\section{CONCLUSION}

This study aim is to describe narcissistic and aggression profile in college student. The results show narcissistic is not only about excessive self-love but an attempt to deny its true identity. On the other side, verbal aggression and hostility are parts of the aggression that is formed through negative thinking about events and malicious intentions against others. The cognitive aspect predominantly influences the emergence of narcissistic personalities. Either verbal aggression or hostility has highest average score in aggression aspects.

Narcissistic and aggression are important to be reduced. Therefore, it is important to develop guidance and counseling services in university. Counseling interventions to reduce either narcissistic or aggression at the university level, especially to potential counselors are important to formulate and investigate further. These issues are important to be resolved immediately, requiring effective and efficient interventions.

\section{REFERENCES}

[1] R. Daniel Ames, et al., "The NPI-16 as a short measure of nercissism", in Journal of Research in Personality, Vol. 40, pp 440-450, doi: 10.1016/j.jrp.2005.03.002, 2005

[2] H. Arnold Buss, The Psychology of Aggression, New York and London: John Wiley and Sons, Inc., 1961

[3] W. Keith Campbell, et al., "Narcissism and Comparative SelfEnhancement Strategies", in Journal of Research in Personality, Vol. 34, pp 329-347. DOI:10.1006/jrpe.2000.2282, 2000

[4] Darrin L Carr, "Relationship among overt and covert narcissism and vocational interests with respect to gender" (Dissertation, Florida State University), 2008

[5] Z. Judith Clark, "Therapist Narcissism", in Proffessional Psychology, Vol. 22, No. 2, pp 141-143, 1991

[6] Demitras-Madran, Andac, "The reliability and validity of the Buss-Perry Aggression Questionnaire (BPAQ)-Turkish Version", in Turkish Journal of Psychiatry 2013 Summer; Vol. 24 No. 2, pp 124-9, 2013

[7] Diagnostic and Statistical Manual of Mental Disorder, Fourth Edition (DSM-IV). Washington, DC: American Psychiatric Association, 1994

[8] J. Gerevinch, et al., "The generalizability of the Buss-Perry Aggression Questionnaire", in Int J Methods Psychiatr Res 2007; Vol. 16 No. 3, pp 124-136, 2007

[9] B. Elizabeth Hurlock, Psikologi Perkembangan. Transl Istiwidayanti \& Soedjarwo. Jakarta: Erlangga, 1999

[10] F. Otto Kernberg, Aggressivity, Narcissism, and Self-Destructiveness in the Psychotherapeutic Relationship: New Development in the Psychopathology and Psycho-therapy of Severe Personality Disorder. New Haven and London: Yale University Press, 2004

[11] Kathy Krajo, What makes narcissists tick. USA, www.OperationDoubes.com, 2007.

[12] Sinead Lambe, et al., The role of narcissism in aggres-sion and violence: A systemic review. Trauma, Violence, \& Abuse, doi:10.1177/1524838016650190, 2016

[13] Mollon, Phil, The fragile self: The structure of narcissis-tic disturbance. London: Whurr Publishers Ltd., 2004

[14] Ongen, DemetErol, "Relationship between narcissism and aggression among non-referred Turkish university students", in Social and Behavioral Sciences, Volume 5, pp 410-415, 2010

[15] R. Raskin and H. Terry, "A principal-components analysis of the Narcissistic Personality Inventory and further evidence of its constructvalidity", in Journal of Personality and Social Psychology, Vol. 54 No. 5, pp 890-902, 1988

[16] Reyna, Cicilia., et al., "The Buss-Perry Aggression Questionnaire: Construct validity and gender invariance among Argentinean adolescents", in International Journal of Psychological Research, Vol. 4 No. 2, pp 30-37, 2011

[17] R. Kathrin, et al., "Lack of empathy in patiens with narcissistic personality disorder", in Psychiatry Research, PSY-06655, 2010

[18] J. W. Santrock, Perkembangan Masa Hidup. Jakarta: Erlangga, 2002

[19] Thomaes, Sander., et al., "Reducing narcissistic aggression by buttressing self-esteem: An experimental field study", in Psychological Science, Vol 20, Issue 12, 2009

[20] Twenge, M. Jean, \& Joshua D. Foster, "Birth cohort increases in narcissistic personality traits among American college students", 19822009, in Social Psychological and Personality Science, Vol. 1 No. 1, pp $99-106,2010$ 